\title{
THE LEGAL PERCEPTION OF THE RISKS OF NANOTECHNOLOGIES IN THE ENVIRONMENT: CHALLENGES AND POSSIBILITIES IN THE CONSTRUCTION OF A FRAMEWORK ${ }^{1}$
}

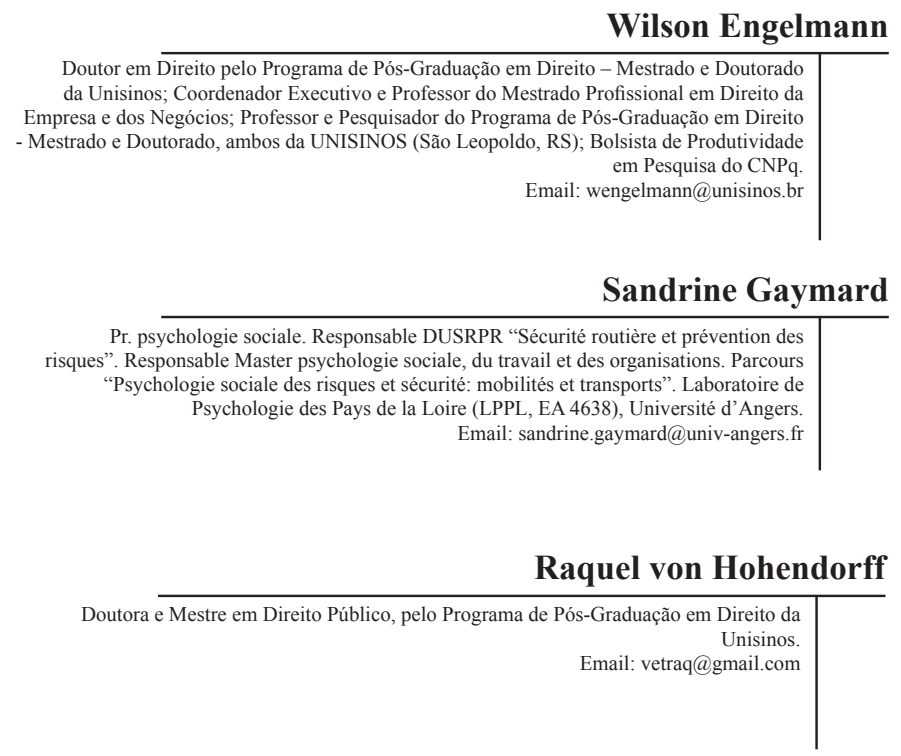

\begin{abstract}
The use of nanoscale is currently growing. The state legislative regulation on the matter is inexistent. There is the rise of self-regulation, as well as the creation of norms by other social actors. The system of Law needs to enter in the context of innovation, granting legal effects to this regulatory production. The temporality of the new forms of regulation and the ability

1 This article is the partial result obtained by the authors in the context of the following research projects:

a) "Nanotechnologies as an example of innovation: in search of structuring elements to evaluate the benefits and risks produced from the nanoscale in the scenario of Responsible Research and Innovation (RRI) and of the Ethical, Legal and Social Impacts - ELSI" - Project Support Research/Call CNPq/ MCTI (Brazil) n. 25/2015 Humanities, Social and Applied Social Sciences; b) "Observatory on the Legal Impacts of Nanotechnologies: structuring essential elements for the development of dialogue between the Sources of Law from regulatory indicators to research and industrial production based on the nano scale" - Support to Research Projects/MCTI/CNPq/Universal 14/2014 (Brazil); c) "The selfregulation of the final disposal of nanotechnological wastes", Public Edict 02/2017 - PESQUISADOR GAÚCHO - PqG/FAPERGS.
\end{abstract}


to deal with future risks and damages represent other challenges for the legal area. The analysis of publications from the OECD and the Web of Science showed that the risk theme is still little discussed in the main scientific journals. From these findings, we present a framework as an regulatory alternative and guideline for the industry that develops products from nanotechnology. Investments in research, categorization and risk analysis throughout the product life cycle is a necessary requirement to guide the governance, the regulation and the self-regulation of the issue.

Key-Words: Nanotechnology; Risks; Framework; Regulation; Selfregulation.

\author{
A PERCEPÇÃO JURÍDICA DOS RISCOS DAS \\ NANOTECNOLOGIAS NO MEIO AMBIENTE: DESAFIOS E \\ POSSIBILIDADES NA CONSTRUÇÃO DE UM FRAMEWORK
}

\title{
RESUMO
}

O uso de nanoescala está crescendo atualmente. A regulação legislativo estadual sobre o assunto é inexistente. Verifica-se o aumento das iniciativas de autorregulação, bem como a criação de normas por parte de outros atores sociais. O Sistema do Direito precisa entrar no contexto da inovação, reconhecendo efeitos jurídicos a essa produção regulatória. A temporalidade das novas formas de regulação e a capacidade de lidar com riscos e danos futuros representam outros desafios para a área jurídica. A análise de publicações da OCDE e da Web of Science mostrou que o tema de risco ainda é pouco discutido nas principais revistas científicas. A partir desses achados, apresenta-se um framework como uma alternativa regulatória e diretriz para a indústria que desenvolve produtos à base das nanotecnologias. Os investimentos em pesquisa, normalização e análise de risco ao longo do ciclo de vida do produto são um requisito necessário para orientar a governança, a regulação e a autorregulação do tema.

Palavras-chave: Nanotecnologias; Riscos; Framework; Regulação; Autorregulação. 


\section{INTRODUCTION}

The twenty-first century is characterized by the emergence of an unprecedented technical-scientific revolution, driven by advances in new products and devices with nanotechnologies. The number of nanotechnology-based products is growing rapidly in the consumer market: according to Nanotechnology Products Database (NPD 2017) in updated data until July 2017, there are 6,879 products that have a nanotechnology-based component, produced in 1,332 companies located in 52 countries. The main sectors which contain the products are food, cosmetics, electronics, household appliances, oil, renewable energy, textiles, medicine, environmental industry, such as water, remediation and water purification, wastewater treatment and soil purification, and sporting goods and fitness. There is a great versatility in the application of nano-scale, which guarantees success and rapid growth and in a short time. As stated by Schwab (2016), nanotechnologies are at the center of the structure called the fourth industrial revolution. In order to understand the implications, effects and possibilities that nanotechnology may bring, it will be necessary to develop the "systemic thinking", ie, integrate and promote interaction between different areas of knowledge, especially through interdisciplinarity, which reveals a way to work, or seek to answer the question: "Why scientists must work together to save the world?" (Interdisciplinarity 2015). This is the main purpose of this article: to study the basis for the integration of Law in research and advances in nanoscale that are being developed by the so-called exact areas. In terms of nanoscience it is observed, in recent years, a movement that went from "concepts" to "application". The Law seeks to integrate the advances of nanotechnology revolution, helping to build the "systemic thinking". This way of thinking will require the implementation of disciplinary barriers in order to understand the challenges that are generated from the nanoscale to the global scale, its impacts and consequences (Ulijn, Riedo 2016).

The functionalist method will be used in the systemic-constructivist perspective of Niklas Luhmann, the risk studies developed by Ulrich Beck, and content analysis by Laurence Bardin.

To support this research methodologically it is assumed the functionalist method, proposed by Luhmann (1990) considering that it "[...] uses the process of relating in order to understand the existing and contingent, and distinguished as comparable [...]." That is, "the 
relationship between problem and solution of the problem here is not regarded as an end in itself; but serves as a guide of the question for other possibilities, such as thread in the search for functional equivalence." It is the systemic-functionalist perspective that seeks to establish this link between the problem and a solution to be built by the constructivist bias, notably by observing the regulatory frameworks being able to cope with the challenges posed by nanotechnology (Luhmann 1990). It is what can be called nanotechnological fact, a phenomenon that is being experienced by society in this historical moment. Its effects are invisible and largely undetermined yet - when considered in the set of techniques, materials and uses of nanotechnologies. In this regard, the Theory of Risk Society (Beck 1992) is used to understand the context of scientific uncertainty and the dimensions of risk and danger. In a Public Lecture given on 15 February 2006, at the London School of Economics, Beck (2006) said: in my first publication in 1986 I described Risk Society as "an inescapable structural condition of advanced industrialization" and criticized the "mathematicized morality" of expert thinking and public discourse on "risk profiling". While policy-oriented risk assessment posited the manageability of risks, he pointed out that "even the most restrained and moderate-objectivist account of risk implications involves a hidden politics, ethics and morality". Risk "is not reducible to the product of probability of occurrence multiplied with the intensity and scope of potential harm". Rather, it is a socially constructed phenomenon, in which some people have a greater capacity to define risks than others. Not all actors really benefit from the reflexivity of risk only those with real scope to define their own risks. Risk exposure is replacing class as the principal inequality of modern society, because of how risk is reflexively defined in the specialized literature: "In risk society relations of definition are to be conceived analogous to Marx's relations of production". The inequalities of definition enable powerful actors to maximize risks for "others" and minimize risks for "themselves". Risk definition, essentially, is a power game. This is especially true for world risk society where Western governments or powerful economic actors define risks for others. "Risks presuppose human decisions. They are the partly positive, partly negative, and are the faced consequences of human decisions and interventions" (Beck 2006). The decision on more specific regulation or not, or even self-regulation, will generate risks, which will be added to the risks that could be generated by the manipulation of the nano scale. Here's the main point that if want to address with this article: would 
be the framework a safe alternative to dealing with the unknown part of the nano world? Taking into account this scenario, the problem that the article seeks to address, is: under what structural elements may make a framework, seeking to bring a guideline for research and product development, with the consequent commercialization based on nanotechnology, an uncertain scenario as to the risk assessment, the absence of legislativestate regulation and the presence of regulatory types developed by public and private actors? Therefore, it formulated the following hypothesis: the principles formulated by NanoAction (2007) can be used as elements for structuring the framework in view of the existence of scattered research on the nano risks and damages that may be generated to human beings and living organisms in general, and the environment, taking into account the loads regulatory texts produced by public and private actors, but without legislative-state participation.

Some toxicological tests carried out with specific materials (such as nano silver, nano carbon tubes and others), have pointed out the existence of hazards. These results, for now, are only samples of a world of possibilities offered by nanotechnology, but they are an indicative that the debate on the issue is necessary and that this is indeed a legal issue to be studied and communicated to consumer public and non-specialist. This method is suitable for interdisciplinary research development, notably from the recently discussions published in the Journal Nature (Interdisciplinarity 2015).

The comprehensive keywords were used to enable data collection in the 80 documents from OECD, which are: "risk", "environmental safety" or "environment", "human health" and "manufactured nanomaterial". These same general keywords serve to structure the words to search the abstracts of publications from Web of Science in the period of 2010-2016. For this latest research, the group of keywords was extended, searching for publications with specifications and details of the searched words of the OECD documents. Through the search in literature database Web of Science with full text available on the Journals Portal CAPES/Brazil (Staff Coordination of Improvement of Higher Level, is a foundation linked to the Ministry of Education of Brazil) dealing with the comprehensive keywords listed above.

In addition, this article uses the content analysis (Bardin 2013) it was carried out in three stages: 1) pre-analysis; 2) exploration of the material: 3) treatment of results, inference and interpretation. 


\section{NANOTECHNOLOGIES: SOME PRELIMINARY CONSIDERATIONS}

A starting point refers to conceptual outline of "Nanotechnology", and "nanomaterial". There is no uniformity in the definition of these two terms in the literature (Stone et al. 2017). Some argue, as Maynard, that one should not work with definitions, for "basing regulations on the term with no scientific justification will do more harm than good" (Maynard 2011). The International Standardization Organization (ISO 2017) through its Technical Committee 229 on Nanotechnologies issued the definition of nanotechnology which contains the same elements of those used over the last decades, that are: "understanding and control of matter and processes at the nanoscale, typically, but not exclusively, below 100 nanometers in one or more dimensions where the onset of size-dependent phenomena usually enables novel applications." To this feature is further added: "utilizing the properties of nanoscale materials which differ from the properties of individual atoms, molecules, and bulk matter, to create improved materials, devices, and systems that exploit these new properties." The first feature relates to the particle size and this may generate the risk, considering the physicochemical changes that are created in this size range. In this scenario, a recent publication of Nature Nanotechnology (2016) states: "But despite these fundamental advances, nanotechnology is confronted with a critical bottleneck. We are still struggling to translate the fundamental advances reported in the scientific literature into tangible technological applications that can be appreciated at the layman's level." There is a duplication of the problem:

\footnotetext{
First, the properties of matter change when scaled up, just like they change when scaled down to the nanoscale; in particular, the level of control can be exerted at the nanoscale or at the single-object level tends to wane at the meso and macroscales or when dealing with a large number of objects. And second, industry is reluctant to invest money in developing large-scale new processes for nanomaterial fabrication unless they are guaranteed a sizeable profitable return.
}

This is also a concern for Warheit (2010): the evaluation of environmental and health risks of nanomaterials is difficult work that involves multi-discipline knowledge and requires global views. Therefore, arguments over and even misunderstandings of nanotoxicity are common. 
The future design of environmentally friendly and biocompatible nanomaterials should be paid much attention. There opens a space of still unknown consequences. For the Law, is generated the necessity to regulate the risks and future damage. What is a great challenge because the Law always assessed the facts of the past, giving them legal effects of this, determining how the behavior should be in the future. In the case of nanotechnology, the effects that may arise - scratches and damages in the present to the future, are still unknown. This is also the problem of State Legislative regulation on the matter: there is still no sufficient scientific information to a formal regulation. It is aimed to signal what would be the regulatory possibilities for this risk scenario, many of which are still unknown, which project to the future an eventuality of damage. Some researches show a disconnection between academic research and its application in industrial scale, which opens new possibilities for risk.

The theme also must deal with the dichotomy between risk and danger. In the environmental scenario it is understood that the danger refers to the intrinsic characteristics of the product or process; meanwhile the risk assumes the degree of exposure to such danger (Foladori, Invernizzi 2016). When examining the life cycle of nanomaterial, it is possible to observe that the danger may be in the following phases/processes: raw materials; process; product; packaging; application/use; reuse/recycle/disposal; end of life (Vaseashta 2015). In the other hand the risk is the worker exposure/ consumer/environment in each of these phases (Shatkin, Kim 2015). Here arises a question: will the last stage "end of life" be effectively the final part, especially considering the possibilities for reuse and recycling? This is another issue that should be further studied.

The life cycle of nanotechnology applied to food, for example, has many uncertainties about the characteristics of the risks because it can affect the bioavailability and nutritional value of food based on their functions. The nanofoods provide the improvement of food security, extending life, improving the flavor and nutrients, allowing detection of pathogens/toxins/pesticides and serving functional foods (He, Hwang 2016). Another example: "Various nanomaterials have been developed for the water remediation" (Santhosh, Velmurugan and Bhatnagar 2016). These two examples show the paradoxical perspective of the nanotechnologies: bring benefits, while bearing problems and difficulties that are not yet known, or partially understand. Therefore, in accordance to Warheit (2010), "the assessments of nanomaterial-related health risks must be accurate 
and verifiable." The attention points are: "nanoparticle physicochemical characterization, as well as consideration of potential routes of exposure, justification of nanoparticle doses, and inclusion of benchmark controls" (Warheit 2010).Here are some aspects that still should be further studied, in order to make feasible the creation of more precise regulatory frameworks.

\section{WHAT IS THE CONTENT OF THE SCIENTIFIC PUBLICA- TION: NANOTECHNOLOGY OR NANOTOXICOLOGY?}

Toxicological effects and impacts of nanomaterials on human health and the environment have not received the same attention from researchers if compared to the positive aspects of products with nanotechnology widely touted in the media and in scientific journals. Compared with nanotoxicology, Nanosafety is widely considered by people. However, nanosafety is not nanotoxicology. Nanotoxicology focuses on the physiology, pathology and biomolecular mechanisms of nanomaterials. Nanosafety focuses on the evaluation of nanomaterial risks in natural environments and biology. The main results and conclusions of nanotoxicology are from the lab, while the main results and conclusions of nanosafety should not match the current environment and real organisms where the field studies are important. Studies on toxicology still need to be improved and deepened. The laboratory studies are important, but the fieldwork is also required. The fieldwork involves the investigation of nanomaterial risks by analyzing the samples from the natural environment, and potential workers exposed to nanomaterials. The laboratory data integrating the results from fieldwork would present real nonmaterial more risks than laboratory experiments alone (Xiangang et al. 2016). At this point there is a great empty space to be fulfill. The number of studies that have been published on the topic of nanosafety speak for themselves. It has been seen an almost exponential rise over the past 15 years or so in the number of articles on nanotoxicology. Although only a couple of hundred papers had appeared on the topic of "Nanomaterials: environmental and health effects" before 2000 this number has exploded to over 10,000 since 2001. Most of those studies, however, do not offer any kind of clear statement on the safety of nanomaterials. On the contrary, most of them are either selfcontradictory or arrive at completely erroneous conclusions (Krug 2014). In a data base research from the Web of Science, between the years of 2010 and 2016, from the key words presented in the abstract of the articles and 
evidenced below, it has been verified the following data:

Table 1 - Publications Web of Science

\begin{tabular}{|c|c|}
\hline number of items & Combinations of words \\
\hline 18,870 & Nanotechnology \\
\hline 5,106 & Nanotechnology and materials \\
\hline 1,258 & ... And environmental \\
\hline 1,219 & $\ldots$ And risks \\
\hline 885 & ... And benefits \\
\hline 473 & ... And regulation \\
\hline 437 & ... And physics \\
\hline 404 & ... And risk assessment \\
\hline 377 & ... And consumer \\
\hline 360 & ... And environmental risks \\
\hline 320 & ... And environmental impacts \\
\hline 312 & ... And waste \\
\hline 264 & ... And nanotoxicology \\
\hline 223 & ... And law \\
\hline 200 & ... And toxicology \\
\hline 175 & ... And consumer risks \\
\hline 87 & ... And social impacts \\
\hline
\end{tabular}

Source: prepared by the authors.

It is observed that the publications on "nanotechnology" are much greater than the concern with issues relating to "toxicology" or the relationship between "nanotechnology and toxicology". The ratio of the publications is very unbalanced, leading to the conclusion that manipulation at the nanoscale is safe. Questions dealing with the impacts, there including human and environmental risks also have publications in low amounts, when compared with the total number of published articles on nanotechnology. Although many articles reviewed for this publication mention concern about the risks, it appears that at the junction of "nanotechnology" and "risks" is found only 1,219 articles that had these words on their abstracts. The result indicates that the interest in the publications continues to be in nanotechnology itself and its applications 
without effectively concerning about research and publication of the effects that working with the nanoscale may cause.

Here is the "conundrum" studied by Owen (2016), in his book with the same title, when he states: "how scientific innovation, increased efficiency, and good intentions can make our energy and climate problems worse", ie, "the point is that, even when we act with what we believe to be the best of intentions, our efforts are often at cross-purposes with our goals. That's the conundrum". The engineered nanoparticles are found in the following sources: consumer products; industrial products and in the manufacturing. So, these are the potential environmental elements to be exposed: air, water and soil. Here is the greatest possibility of risks, and the "conundrum": even when it is acted in a way that is believed to be the best of intentions (water remediation, healthier food, drugs with fewer adverse effects, clothing that need to be washed less often, once they are self-cleaning, among other possibilities), our efforts are constantly at cross-purposes with our goals (despite the good opportunity expressed by nanotechnologies, they also open possibilities for the generation of unknown risks).

Another purpose of this study, based on the 80 documents of the OECD (2017) "Series on the Safety of Manufactured Nanomaterials", is to analyze the perception of risks and the way that the assign legal effects of the unknown future damages that might be generated from the manipulation of the nanoscale, especially in relation to human health and the preservation of the environment. Comprehensive keywords were used to enable data collection in the 80 documents, which are: "risk", "environmental safety" or "environment", "human health" and "manufactured nanomaterial". The word "nanomaterial manufactured" has 4,934 repetitions; "Risk" has 4,214 repetitions; "Environment" has 2,204 repetitions and "human health" has 1,478 repetitions. This shows extreme concern about the risks which nanomaterials could pose to the environment and human health. The observed keywords show that manufactured nanomaterials may generate risks for the environment and human health, with little concern for the environmental safety, which has only 48 repetitions. For this reason it is important to structure a framework of the legal risk management tool for nanotechnology companies to gather information and deal with future uncertainties and damages, through the evaluation of the steps of the nanomaterial's life cycle. In this scenario is relevant an adequate evaluation of the ethical and social impacts in the structuring of self-regulation. 
Comparing the data shown in Table 1 with the findings in the 80 documents of the OECD, it is observed that in both data the concern is with nanotechnology and nanomaterials. The fear of the risks and impacts that nanomaterials may cause in relation to human health and the environment is inexplicit. Therefore, despite the preoccupation in announcing risks and impacts, in fact, the main focus is still given to the results and possibilities that nano scale can provide. These data shows that there is still much to be done. The risks should also be studied with the same emphasis given to applications. There is also an obstacle to a state legislative regulation: while the risks are unknown, creating traditional formal regulation is very complicated.

Nanoparticles access the human body in different ways, such as by inhalation, skin contact and oral ingestion (food, water, drugs, etc.), which can generate numerous reactions. If the researches to study these new reactions are scarce, what to say about effective and aligned actions to monitor "nanopathologies"? (Gatti, Montanari 2008). It can be said that the point of view of human health research development to analyze the toxicity of nanoparticles and consequences of associations with nanoparticles that accumulate in the human body and the environment is still a new field and it needs many investments in science to advance.

\section{REGULATORY CHALLENGES: ARE WE ON THE RIGHT TRACK?}

A fairly complete survey of existing regulations in the US, European Union, some Asian countries like Japan, South Korea and China, in addition to the Latin American countries, especially Brazil, can be found in Wackera, Proykova and Santos (2016). The regulatory mechanisms already developed will not be addressed, they are already sufficiently published. What is intended to show are some regulatory initiatives that have emerged in recent years and which are not related to state legislative output, as shown in this study: "A closer examination of the key actors in the networks further shows the interrelation between public and private actors in regulatory innovation, and the role of intermediary organizations. On the other hand, most of the global market has no distinct regulations regarding consumer products of nanomaterials". Considering nanosafety of humans and the environment, are highlighted the following international organizations which edited structures with regulatory characteristics: the 
international organizations (OECD, REACH-Registration, Evaluation, authorization and Restriction of Chemicals, and ISO, etc.) and the developed countries (USA, EU and Japan, etc.) are trying to create guidelines and standardization for toxic evaluation and the regulation plans or research projects for nanotechnology. Those organizations also indicate regulatory perspectives for intergovernmental organizations such as the WHO. "The analysis may also suggest that by going through private international decision making venues, national regulators can strategically diffuse their regulatory approaches to other countries" (Park, Yeo 2016). "Two of the largest economic actors, the EU and the US, have made very different regulatory decisions toward nanotechnology. The EU introduced an official definition of nanotechnology and created several nano-specific new regulations in recent years, whereas the United States has followed more of a "wait and see" policy (Rodine-Hardy 2016).

Risk and damages may find themselves in different levels in the same life cycle if a nanomaterial. A guideline that can advise the proposed Life Cycle Assessment is presented as follows: the development of "nanoecotoxicology". This new subdiscipline of ecotoxicology faces two important and challenging problems: "the analysis of the safety of nanotechnologies in the natural environment and the promotion of sustainable development while mitigating the potential pitfalls of innovative nanotechnologies" (Kahru, Ivask 2013). What means: the growth on applications of nanotechnology should be guided by sustainability, focused on preservation of life on Earth for present and future generations of living beings - human or not. The Life Cycle Assessment, according to the researchers Hischier and Walser (2012), "is a comprehensive framework that quantifies ecological and human health impacts or the product or system over its complete life cycle". They identified 17 studies with different forms of structuration of the Life Cycle Assessment.

The risk assessment is the basis for regulatory actions with respect to nanomaterials. The question of contextualization, categorization and analysis of risk that may arise from nanoparticles in the various steps that are part of the life cycle is of fundamental importance. The testing of current and potential nanomaterials is very challenging: first, because of the large number of nanomaterials and second, because of small changes in the nanomaterial, such as its physical structure or surface coatings, what can significantly change its interactions with biological and environmental systems, especially at the molecular and cellular level. Consequently, it is 
critical that in assessing risk to health and safety, ie, unwanted and negative interactions, one should be able to identify the mechanism by which these negative interactions operate. Such interactions should be dimensioned in scientific laboratories and during stages of the life cycle (Uniform Description System for Materials on the Nanoscale 2016).

What is proposed in the sequence is to conduct a practical approach of an application of the regulation model, to be followed by the industrial sector, as a way to mitigate any future damage that may arise from the use of nano scale in relation to workers and consumers' health, in addition to environmental issues.

\section{STRUCTURING THE FRAMEWORK AS A REGULATORY ALTERNATIVE}

The framework that is proposed, will be inspired by the following key elements: a) definition of the nanotechnology and nanomaterial, according to ISO and the OECD; nanomaterials as new substances; b) thresholds: nanomaterials should be considered that, due to their properties, are much more reactive than generally their bulk counterparts, thereby increasing the risk of harmful impact by nanomaterials compared to an equivalent mass of bulk materials; c) testing protocols; d) market surveillance and e) consumer transparency and worker's protection (Azoulay, Buonsante 2014). Furthermore, to deal with the risk of future damage, in a context of scientific uncertainty about its extent, the framework will be guided by the precautionary principle, from practices to consider in precaucionary decision-making: a) comprehensive treatment of information and knowledge; b) integration of multiple values in decisionmaking; c) a more democratic decision; d) defining the range of solutions and e) using the common procedural framework (the regulatory framework is required, which is coherent, proportionate and effective, and also suited to the nature of the potential dangers, with common procedures that organize research, expertise, public information and debate (Gonçalves 2013).

According to these coordinates, the steps of the framework should be able to answer the following questions, seeking to guide the decision-maker (Stone et al. 2017):

1) Does any modification introduced actually affect design properties (chemical composition, crystallinity, surface chemistry/charge, primary size, particle size distribution and its evolution in testing and in 
life-cycle media)?

2) If yes, does the modification affect risk determinant properties (structural alerts) that can be considered relevant for estimating potential hazardous?

3) If yes, do the changes in risk determinant properties reduce in vitro or in vivo toxicity according to the established biomarkers of mode of action? Evidence collected can be used to read-across risk for human health and establishing new exposure limits.

4) If yes, different scenarios can occur:

i) Tested toxicology endpoints do not show a coherent response (e.g. some results show the reduction of toxicity potential, while others demonstrate an increase); in this case, the further mechanistic investigation is necessary to better correlate changes in design and risk determinant properties and toxicology end points);

ii) Tested toxicology endpoints show the coherent response (e.g. all the results for the selected modification show an increase or decrease of potential toxicity); in this case, the cost/effectiveness evaluation should not be considered before discharging or validating the design solution proposed.

Those questions might take as a start point one or more regulatory texts of non-state-owned legislative origin which are summarized in Wackera, Proykova and Santos (2016) and in Stone et al (2017). In all steps of the framework it is recommended to practice the following guiding principles: a) precautionary foundation; b) health and safety of the public and workers; c) environmental protection; d) transparency; e) public participation $\mathrm{f}$ ) inclusion of broader impacts and g) manufacturer liability (NanoAction 2007).

\section{Pic. 1: Framework with the Life Cycle Assessment}
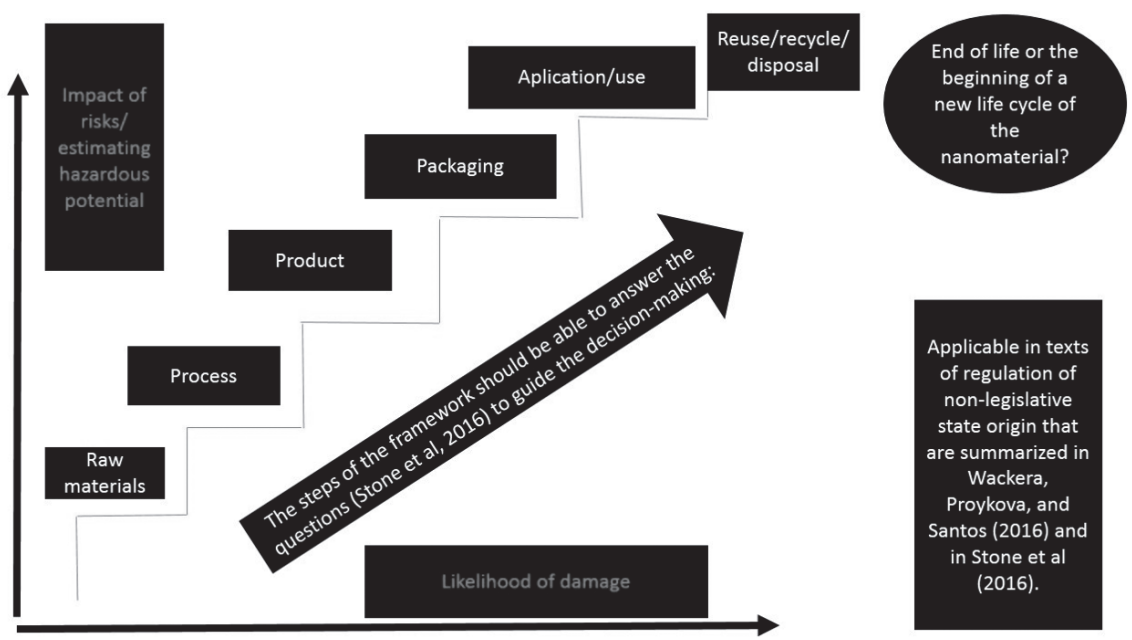

Source: prepared by the authors.

In the various steps of this framework is a central point: the 
identification of risks. They will have different intensity and impact depending on the type of the nanoparticle, of its size and environment in which they will be exposed, also it should be taken into account that the exposure may occur by different pathways: direct exposure (occupational, consumer and/or environment) or indirect (general population exposure through the environment), each one with its own mitigation measures (Stone et al 2016). Therefore, the bigger the threshold of the "impact of risks or estimating potential hazardous" at the junction with the "likelihood of damage", much more attention has to be given to the various stages of the life cycle. The records of events, reactions in each step should be noted, generating information. Moreover, a fundamental point is the last step, when it should answer the question: "end of life or beginning of a new cycle of the nanomaterial life?", especially when working with recycling.

\section{CONCLUSION}

The construction and use of frameworks, with the application of small adjustment on existing nanotechnologies, and the other legal texts in force in each country, although not nano-specific, with application to nano scale, is the alternative to be adopted at this moment. Throughout the life cycle, the explicit coordinates in the framework should be observed by all steps of a life cycle of a nanomaterial, the so-called "shared responsibility", according to Brazilian Law no 12,305, of August 2, 2010 (Brazil 2017): "Set of individual and chained assignments of manufacturers, importers, distributors and traders, consumers and owners of public services for urban cleaning and solid waste management to minimize the volume of solid waste and generated waste, as well as to reduce impacts on human health and environmental quality of the resulting product life-cycle management, under this Act" (Article 3, XVII). In the various steps of the framework should be created information on nanomaterials, aimed at filling the gaps that currently exist. This is the side of the industrial production of nanotechnologies. At the same time, should increase the research on nanotoxicological effects, both in vivo as in vitro. Therefore the data collected, publications, at this point, are still very small. In the various steps examined, the Law intends to be present, seeking to legally structure the information that will be collected. From this information, is possible to review each step by adding new non-state legislative regulatory texts that might arise. In a long term, and with more accurate information 
it will be possible to plan the structure of regulatory texts that meet the specific requirements of different countries, through international treaties. As a result of globalization and the characteristics of the "risk society", it has not been thought about localized regulatory texts, but to extend beyond their scopes to the territory of each country. The precautionary principle will be the liaison between the nanotechnologies we have and the nanotechnologies we want.

The panorama presented throughout the article, seeking to respond the problem formulated in the Introduction, points to the confirmation of the hypothesis that structured this article, points out that there was a paradoxical result, indicating a significant gap: despite extracted publications from the database Web of Science underlined the importance of the study of the risk, there are still few scientific publications, showing depth research on this item, especially with the preoccupation regarding the human health and environmental preservation for present and future generations. The absence of legislative-state regulation increases the importance of regulatory texts already published by the work of public and private actors, as well as their effective usage throughout the various steps of the life cycle, from the possibilities produced by the framework, where the social, environmental and legal impacts generated by nanotechnologies can be evaluated.

\section{REFERENCES:}

Azoulay, D., Buonsante, V. (2014). "Regulation of nanomaterials in the US: Proposed measures to fill in the gap". European Journal of Risk Regulation 2: 228-235. doi: https://doi.org/10.1017/S1867299X00003652.

Bardin, L. (2013). L'Analyse De Contenu. 2e Édition. Paris: PUF.

Beck, U. (2006). "Living in the world risk society". A Hobhouse Memorial Public Lecture given on Wednesday 15 February 2006 at the London School of economics. Economy and Society 35 (3): 329-45. doi: http://dx.doi.org/10.1080/03085140600844902.

Beck, U. (1992). Risk Society: towards a new modernity (Published in association with Theory, Culture \& Society). London: SAGE Publications.

Brazil. (2017). Law n. 12,305, of August 2, 2010. Retrieved May 18, 2017, from http://www.planalto.gov.br/ccivil_03/_ato2007-2010/2010/lei/ 
112305.htm.

Foladori, G., Invernizzi, N.(2016). "La Regulación de las Nanotechnologies: una mirada desde las diferencias EUA-UE". Vigil. Sanit. Debate. 4 (2): 8-20. doi: 10.3395 / 2317-269x.00726.

Gatti, A. M., Montanari, S. (2008). Nanopathology. The health impact of nanoparticles. Singapore: Pan Stanford.

Gonçalves, V. (2013). "Critical approach of the use of economic models in precautionary risk management". European Journal of Risk Regulation 3: 335-45. Retrieved May 18, 2017, from http://ejrr.lexxion.eu/article/ EJRR/2013/3/286.

He, X., Hwang, H.-M. (2016). "Nanotechnology in food science: functionality, applicability, and safety assessment". Journal of Food and Drug Analysis, 24 (4): 671-81. Retrieved May 18, 2017, from http://www. jfda-online.com/article/S1021-9498(16)30075-8/pdf.

Hischier, R.; Walser, T. (2012). "Life cycle assessment of engineered nanomaterials: state of the art and strategies to Overcome existing gaps". Science of Total Environment 425: 271-82. doi: 10.1016 / j.scitotenv.2012.03.001.

Interdisciplinarity. (2015). Nature 525: 325. Retrieved May 18, 2017, from http://www.nature.com/news/interdisciplinarity-1.18295.

ISO/TC 229. (2017). Retrieved May 18, 2017, from http://www.iso.org/ iso/iso_technical_committee?commid $=381983$.

Kahru, A., Ivask, T. H. E. (2013). "Mapping the Dawn of Nanoecotoxicological Research". ACC Chem. Res 46 (3): 823-33. doi: 10.1021/ar3000212.

Krug, H. F. (2014). "Nanosafety Research-Are We on the Right Track?" Angewandte Chemie International Edition 53: 12304-319. doi: 10.1002/ anie.201403367.

Luhmann, N. (1990). Sociedad y sistema: la ambición de la teoría. Barcelona: Paidós.

Maynard, A. D. (2011). "Do not define nanomaterials". Nature, 475: 31. Retrieved May 18, 2017, from http:/www.nature.com/nature/journal/ v475/n7354/full/475031a.html. 
NanoAction. (2007). "Principles for the Oversight of Nanotechnologies and Nanomaterials". Retrieved May 18, 2017, from http://www. centerforfoodsafety.org/files/final-pdf-principles-for-oversight-ofnanotechnologies_80684.pdf.

OECD. (2017). "Working Party on Nanotechnology (WPN): Vision Statement." Retrieved May 18, 2017, from https://www.oecd.org/sti/nano/ oecdworkingpartyonnanotechnologywpnvisionstatement.htm.

Owen, D. (2011). The Conundrum: How Scientific Innovation, Increased Efficiency, and Good Intentions Can Make Our Energy and Climate Problems Worse. New York: Penguin Group.

Park, H.-G., Yeo, M.-K. (2016). "Nanomaterial regulatory policy for human health and environment". Mol Toxicol. 12: 223-36. doi: 10.1007/ s13273-016-0027-9.

Rodine-Hardy, K. (2016). "Nanotechnology and Global Environmental Politics: Transatlantic Divergence". Global Evironmental Politics 16 (3): 89-105. doi: 10.1162/ GLEP_a_00367.

Santhosh, C., Velmurugan, V., Jacob, G., Bhatnagar, A. (2016). "Role of nanomaterials in water treatment applications: a review". Chemical Engineering Journal 306: 1116-1137. doi: http://dx.doi.org/10.1016/j. cej.2016.08.053.

Shatkin, J. A., Kim, B. (2015). "Cellulose nanomaterials: life cycle risk assessment, and environmental health and safety roadmap" Environ. Sci .: Nano, 2: 477-99. doi: 10.1039/C5EN00059A.

Schwab, K. (2016). The Fourth Industrial Revolution. São Paulo: Edipro.

Stone, V. et al. (2017). "Research priorities relevant to development or updating of nano-relevant regulations and guidelines". Retrieved May 18, 2017, from http://www.safenano.org/news/news-articles/eu-nanosafetycluster-publishes-research-regulatory-roadmap.

Stone, V. et al. (2016). "Research priorities relevant to development or updating of nano-relevant regulations and guidelines". Retrieved May 18, 2017, from http://jusnano.blogspot.com.br/2017/01/research-prioritiesrelevant-to.html.

Ulijn, R. V., Riedo, E. (2016). "Learning to 'think systems"”. Nat. Nanotech 11: 824. Retrieved May 18, 2017, from http://www.nature.com/nnano/ 
journal/v11/n9/full/nnano.2016.161.html.

Uniform Description System for Materials on the Nanoscale. (2016). Prepared by the CODATA-VAMAS Working Group On the Description of Nanomaterials, Version 2.0 25 May 2016. Retrieved May 18, 2017, from http://www.codata.org/nanomaterials.

Vaseashta, A. (2015). Life Cycle Analysis of Nanoparticles: risk, assessment, and sustainability. Lancaster, USA: DEStech Publications.

Wackera, M. G., Proykova, A. and Santos, G. M. L. (2016). "Dealing with Nanosafety around the globe-Regulation vs. Innovation". International Journal of Pharmaceutics 509: 95-106. doi: http://dx.doi.org/10.1016/j. ijpharm.2016.05.015.

Warheit, D. B. (2010). "Debunking Some Misconceptions about Nanotoxicology". Nano Lett 10 (12): 4777-82. doi: 10.1021/nl103432w.

Xiangang, H., Dandan L., Gao Y. and Zhou, Q. (2016). "Knowledge gaps between nanotoxicological research and nanomaterial safety". Environment International 94: 8-23. doi: http://dx.doi.org/10.1016/j. envint.2016.05.001.

\section{Como citar este artigo (ABNT):}

ENGELMANN, Wilson; GAYMARD, Sandrine; HOHENDORFF, Raquel von. The legal perception of the risks of nanotechnologies in the environment: challenges and possibilities in the construction of a framework. Veredas do Direito, Belo Horizonte, v. 15, n. 33, p. 243-261, set./dez. 2018. Disponível em: <http://www.domhelder.edu.br/revista/ index.php/veredas/article/view/1298>. Acesso em: dia mês. ano.

Artigo recebido em: 25/06/2018 Artigo aceito em: 20/11/2018 